\title{
Menu price presentation influences on consumer purchase behavior in restaurants
}

\author{
Sybil S. Yang \\ Corresponding Author \\ Cornell University \\ Sheryl E. Kimes \\ Cornell University \\ Mauro M. Sessarego \\ Culinary Institute of America
}

\section{Article Info}

Keywords: Menu design, Price format, Menu psychology, Dollar sign, Restaurant consumer behavior, Price presentation

\section{A bstract}

Empirical research on menu design and price presentation thus far has focused primarily on attitudinal affects on consumers and not necessarily on actual purchase behavior. This experiment uses price presentation manipulations to determine what price formats may affect consumer purchase behavior. Overall, price presentation was not found to be a significant predictor of consumer spending in an upscale restaurant environment. However, results did show a significant reduction in spending when formats with monetary cues such as the word "dollars" or the symbol "\$" were used. In addition, no significant spending differences between numerical and scripted presentation formats were found.

\section{Introduction}

The act of giving a menu to a restaurant guest has been described as, "The ability to place an advertisement in every customer's hand before they part with their money" (Kelson, 1994). In this vein, a plethora of consultants, graphic designers and restaurant revenue management practitioners have sought to successfully use clever copy, shrewd 'value pricing' ploys, design layout, and typography to impact consumer attitudes and purchase behavior. Though there is some evidence relating these design tactics to increased consumer attention, no relationship has been established between attention and purchase behavior (Gallup Report, 1987; Reynolds et al., 2005).

Existing hospitality management research suggests consumer purchase behavior and value and quality assessments can be affected by changes in menu item labeling (Wansink et al., 2001). Specifically Wansink and his colleagues found that descriptive labels can increase an item's purchase frequency as well as consumers' satisfaction towards the purchase. However, the increase in satisfaction was not reflected in an increased willingness to pay. Other research also indicates that value-oriented guests may be attitudinally influenced by odd-numbered or 'value' price presentations (Carmin and Norkus, 1990; Naipaul and Parsa, 2001). For example, Naipaul and Parsa found guests perceived a quick service menu to be more 'value' oriented when its prices are presented with ' 9 ' endings, than when it was presented with '0' price endings. 
In the same study, fine dining establishments were perceived as of a higher quality when its menu prices ended with ' $0 \mathrm{~s}$,' than when they ended with ' 9 s.' But again, this influential relationship between presentation and perception was not been tested in the context of purchase behavior.

Price presentation research conducted on food purchase behavior in supermarket settings suggest that price presentation differences based on positioning, size, or use of symbols, can affect purchase behavior for non priceconscious consumers (Miyazaki et al., 2000). In this study, we examine a subset of these price presentation factors in a restaurant setting, to determine whether restaurant menu price presentation can affect consumer purchase behavior.

It is common to find a wide variety of price formats used in restaurant menus. For example, a 20-dollar menu item is often presented to a guest in multiple formats: "\$20.00", "20.", or twenty dollars (written out in script). Empirical evidence shows that individuals process Arabic numerals and their written-word counterparts in much the same way (Dehaene and Akhavein, 1995). However, numerical price presentations may carry differences in semantic salience (Kim and Kachersky, 2006). So, although the semantic meaning underlying each price presentation is the same (e.g. $\$ 20=20=$ twenty dollars), the differences in salience indicates that various presentation methods may affect different levels of attention, awareness and attitude in some consumers.

Kim and Kachersky (2006) propose that Arabic numerals may affect more attention in situations which facilitate computational processes. So for example, although the mind processes the physical count of " 20 " and "twenty" in much the same way, a " 20 " presentation on a restaurant menu may more readily stick in a consumer's mind if the person approaches the menu with a computational attitude. This increased awareness, a reminder of payment and cost, may activate what Zellermayer (1996) refers to as the "pain of paying." In essence, the pain of paying refers to a consumer's reliance upon an immediate gut reaction to evaluate whether a product's immediate (not anticipated) pleasure is worth its immediate pain. If the immediate pain is greater than the immediate pleasure, then the product is less likely to be purchased. Thus, this experiment was conducted with the expectation that:

H1. Menus that use numerical price formats will result in lower consumer spending than those that spell their prices out in script.

Aside from the script versus Arabic numeral difference in presentation, research in cognitive psychology has shown that behaviors and attitudes can be altered subconsciously through priming. In general, priming refers to the idea that attitudes can be subliminally awakened or biased by the presence of some relevant cue. For example, research has shown that pictures or words can make people more culturally or socially biased (Devine, 1989), change their mood (Blaney, 1986), and that icons such as flags can make people more patriotic (Hong et al., 2000), all without a person's conscious awareness that their attitudes have been affected. Though little research has been conducted on the behavioral impact of priming with monetary symbols, the presence of a strong, culturally salient icon such as the dollar sign (\$) may not only increase price salience, but it may also activate a host of "pain of payment" reactions by the consumer. Thus, we also hypothesize that:

H2. Menus that present prices with a "\$" symbol will yield lower consumer spending than those that do not. 


\section{Methods}

The experiment was designed and executed in St. Andrews Cafe (St. Andrews), an upscale-casual restaurant at the Culinary Institute of America (CIA) in Hyde Park, NY. The St. Andrews dining room is operated by the ClA's fourth semester Associates Degree program students under the supervision of a faculty maitre $d^{\prime}$. The restaurant's guest demographics include a variety of tourists, local businesspersons, and friends and family of the CIA's students, alumni, and administrators. Although guests were not informed of the purpose of the study, they were told that data collected from the study would contribute to the students' educational experience.

From August 6th to November 19th of 2007, the St. Andrews lunch meal period used three versions of its typical menu. Each of the three menu versions was identical in content, however they differed in both price format and the color of the elastic binding used to secure the menu cover. Each menu comprised of a single landscape-printed 8.5 in. $x 11$ in. sheet fold in half to create two 5.5 in. $\times 8.5$ in. facing pages. The paper sheet was banded to a glossy cardstock cover with an elastic band in one of three colors (white, green, or red) depending on the menu format treatment applied. Menus with prices presented in a "\$XX.XX" format were banded with green elastic. Menus with a "XX." price format were banded with white elastic, and menus with a spelled-out (scripted) price format (e.g. "twenty dollars") were banded with red elastic.

Lunch parties who patronized St. Andrews during the experiment period were randomly assigned a menu treatment. Each member of a single party received the same menu treatment, thus the unit of analysis used for the experiment was on a per table basis. At the end of each meal, but before the check was presented, each party was asked to complete a survey. Each survey was referenced back to its respective check data via the Culinary Institute's MICROS point of sales system (POS). Data collected from the POS included: total check (with and without tax and tip), party size, and dining duration. Of the 256 completed surveys collected, 55 (or 21\%) showed party size discrepancies between the server's recorded guest count for the table, and the guest count recorded in the POS system. These surveys were discarded and the data analysis for this study includes only the 201 samples where party size between the two sources matched.

The study was a between subjects experiment design where total check before tax and tip (total check) was compared across the three menu treatment manipulations. Data analysis incorporated party size, dining duration, and an interaction term of the two variables as covariates to control for party size effects on total check. Merit-based tip for the total check was also added as a covariate to control for general variations in consumers' propensity to spend. Finally, variation due to individual table characteristics (such as location and ambiance) was controlled for by integrating table number as a categorical variable. Analysis of covariance (ANCOVA) was used to determine whether the price typography manipulation affected total check. The ANCOVA was then supplemented with linear contrasts between treatment conditions to determine if significant differences in total check existed between the typographical formats.

\section{Res u I t s}

Summary results from the ANCOVA, controlling for party size, dining duration, individual propensity to spend (as measured by tipping behavior), and individual table variation are shown in Table 1. Overall, the model was able to account 
for $82.3 \%$ of the variation observed in the data. Predictably, party size, dining duration, and tip amount held the most explanatory power for total check ( $p<0.0001$ for each of the three variables). Individual table location showed moderately significant effects on total check $(p<0.053)$.

Even after controlling for all the covariates mentioned above, the overall price format effect on total check was still not significant $(p>0.144)$. However, linear contrasts between price format conditions (Table 2) showed an estimated $\$ 5.55$ difference in total checks between the "XX." and non-“XX." formats ("\$XX.XX" and scripted) $(p<0.05)$. Thus, after controlling for the more major predictors of a party's total check, menus that utilized a numerical price format without an overt reference to money, yield an average $\$ 5.55$ more in spending than menus with prices printed with either a dollar sign or written in script. Based on St. Andrews' average check and party sizes, this \$5.55 increase in total check translates to a $8.15 \%$ increase in average spending per person (from an average $\$ 23.00$ per person to $\$ 24.87$ per person). Based on this result, Hypothesis One, that menus with numerical price formats will yield lower consumer spending than those with scripted prices, was rejected.

In addition, no significant differences were detected between the "\$XX.XX" and scripted formats $(p>0.99)$. This finding is counter to expectations in Hypothesis Two, that menus which use the "\$" symbol will yield lower consumer spending than those that do not.

Table 1

Summary ANCOVA results

\begin{tabular}{|c|c|c|c|c|}
\hline \multirow[t]{2}{*}{ Effect on total check (\$) by } & \multirow[t]{2}{*}{ Estimate } & \multirow[t]{2}{*}{ Standard error } & \multicolumn{2}{|l|}{ Adjusted $R^{2}=0.823$} \\
\hline & & & Statistical test & $\operatorname{Prob}>|\mathrm{t}|$ \\
\hline Intercept & $\$(36.95)$ & $\$ 6.63$ & $\{(171)>-5.57$ & $<.0001^{-}$ \\
\hline Party size & $\$ 16.28$ & $\$ 1.81$ & $t(171)>8.97$ & $<.0001^{-\infty}$ \\
\hline Dining duration (min) & $\$ 0.46$ & $\$ 0.06$ & $t(171)>7.43$ & $<.0001^{-\infty}$ \\
\hline Tip amount ${ }^{2}$ & $\$ 0.94$ & $\$ 0.21$ & $t(171)>4.49$ & $<.0001^{-}$ \\
\hline (\# In party -3$) \times($ dining duration (Min) -94$)$ & $\$ 0.18$ & $\$ 0.04$ & $t(171)>4.52$ & $<.0001^{-}$ \\
\hline Table (individual locations) ${ }^{\mathrm{b}}$ & & & $F(23,171)>1.57$ & 0.0534 \\
\hline Price format & & & $F(2,171)>1.95$ & 0.1447 \\
\hline$x \times$ & $\$ 3.70$ & $\$ 1.87$ & $(171)>1.98$ & $0.0497^{*}$ \\
\hline $5 \times X \times X$ & $\$(1.85)$ & $\$ 1.89$ & $t(171)>-0.98$ & 0.3306 \\
\hline Scripted & $\$(1.85)$ & $\$ 1.84$ & $t(171)>-1.00$ & 0.3166 \\
\hline
\end{tabular}

a An ANOVA showed tipping behavior, as a measure of propensity to spend, was not influenced by menu treatment conditions. $F(2,198)<0.38$.

b Three table locations showed statistically significant total checks.

- Significance level of $\mathrm{p}<0.05$.

- Significance level of $\mathrm{p}<0.0001$.

Table 2

Linear contrast of menu treatments

\begin{tabular}{lcccc}
\hline Contrast & \multicolumn{4}{c}{ Mean difference Standard error Test statistic Prob $>F$} \\
\hline XX. vs. (\$XXXX \& scripted) $\$ 5.55$ & $\$ 2.81$ & 1.98 & $0.0497^{*}$ \\
\$XXXX vs. scripted & $\$ 0.00$ & $\$ 3.24$ & 0.00 & 0.9990 \\
XX. vs. \$XX.XX & $\$ 5.55$ & $\$ 3.28$ & 1.69 & 0.0929 \\
XX. vs. scripted & $\$ 5.55$ & $\$ 3.20$ & 1.74 & 0.0843 \\
\hline
\end{tabular}

Linear contrasts of menu treatment means revealed a significant difference between the mean total checkaffected by the "XX" price format and other ( $\$ X X . X X$ and script) formats $(p<0.05)$. 


\section{Discussion}

The results of this experiment add two pieces of evidence to the discussion on menu design and menu psychology. First, larger operational factors have significantly greater impact on purchase behavior than price typography. Specifically, party size, dining duration, table location, and consumers' innate propensity to spend, each play a significantly greater role than price typography in affecting the total check size for a party. However, the second finding from this study is that statistically significant spending differences were found depending on the menu price format used.

Numerical price formats were expected to activate greater price awareness than written or scripted formats, resulting in more cautious spending behavior. That prices presented in the "XX." format actually resulted in higher spending than scripted prices was surprising. However, the scripted presentation format used in this experiment included the word "dollars" at the end of each price. Perhaps the act of repeatedly reading the word "dollars" acted as an unintentional prime and activated concepts of cost or price, initiated a pain of paying, and subsequently caused guests to spend less. That menus which used a dollar sign or the word "dollars" yielded statistically similar spending suggests consumers interpreted the two formats similarly. Thus, any potential differences in affect between scripted and 'dollar-signed' formats may have been masked by the presence of monetary cues ("dollars" or "\$"). That being said, the one price format tested with no overt reference to money resulted in greater consumer spending.

The results of this experiment raise more questions than it answers. Avenues for future research should include an examination on the priming effects of monetary symbols on purchase behavior. Certainly guests perceive the existence of the word "dollars" or the dollar symbol on their menus, but does that perception come with awareness on possible affects? It may also be interesting to examine under what operational conditions these menu typography effects might play a larger role in total spending. For example, this experiment took place in an upscale-casual restaurant, where consumers had plenty of time, information, and service to aid in the ordering process. In this case, price was only one aspect of the decision making process. In quick service or fast casual environments where the consumer may be more price conscious to begin with, has less time, less product information, and less service interaction, the decision making process may overweight the importance of prominent or salient price information. Significant results in this experiment were only obtained after controlling for a host of operational factors, including guests' innate propensity to spend.

Based on the data collected in this study, operationalizing price typography comes down to this: changing the menu typography is like picking the low hanging fruit when it comes to squeezing every last cent from an existing business: the yield may not be large, but it is easy to do, and there is very little downside to form a typographical strategy for the menu. It is better to use a format without any overt references to money, but from there whether prices are represented numerically or spelled out in words, it does not really matter.

\section{Acknowledgements}

The authors would like to thank The Culinary Institute of America's Menu Research and Flavor Discovery Initiative for its encouragement and support in this research project. 


\section{References}

Blaney, P.H., 1986. Affect and memory: a review. Psychological Bulletin 99, 229246.

Carmin,J., Norkus, G.X., 1990. Pricing strategies for menus: magic or myth? Cornell Hotel \& Restaurant Administration Quarterly $31(3), 44$.

Dehaene, S., Akhavein, R., 1995. Attention, automaticity, and levels of representation in number processing. Journal of Experimental Psychology/Learning, Memory \& Cognition 21 (2), 314.

Devine, P.G., 1989. Stereotypes and prejudice-their automatic and controlled components. Journal of Personality and Social Psychology 56 (1), 5-18.

Gallup Report, 1987. Through the eyes of the customer. The Gallup Monthly Report on Eating Out 7 (3), 1-9.

Hong, Y.Y., Morris, M.W., Chiu, C.Y., Benet-Martinez, V., 2000. Multicultural minds- a dynamic constructivist approach to culture and cognition. American Psychologist 55 (7), 709-720.

Kim, H.M, Kachersky, L., 2006. Dimensions of price salience: a conceptual framework for perceptions of multi-dimensional prices. Journal of Product \& Brand Management 15 (2), 139-147.

Kelson, A.H., 1994. The ten commandments for menu success. Restaurant Hospitality 78 (7), 103.

Miyazaki, A.D., Sprott, D.E., Manning, K.C., 2000. Unit prices on retail shelf labels: an assessment of information prominence. Journal of Retailing $76(1), 93-112$.

Naipaul, S., Parsa, H.G., 2001. Menu price endings that communicate value and quality. Cornell Hotel \& Restaurant Administration Quarterly $42(1), 26$.

Reynolds, D., Merritt, E.A., Pinckney, S., 2005. Understanding menu psychology: an empirical investigation of menu design and consumer response. International Journal of Hospitality \& Tourism Administration 6 (1) 1-10.

Wansink, B., Painter, J., Van Ittersum, K., 2001. Descriptive menu labels' effect on sales. Cornell Hotel \& Restaurant Administration Quarterly 42 (6) 68.

Zellermayer, O., 1996. The Pain of Paying. Unpublished dissertation, Department of Social and Decision Sciences. Carnegie Mellon University, Pittsburgh, PA. 